\title{
Adjuvant Chemotherapy for Low-Clinical-Risk Breast Cancer Defined by Modified Version of Adjuvant! Online: A Propensity Score Matched SEER Analysis
}

\author{
Jiefeng Huang ${ }^{a, b}$ Zhiyong Wu ${ }^{c}$ Zechun Zhang ${ }^{c} \quad$ Jie Lia,b Yunhai Lia,b \\ Guosheng Ren ${ }^{a, b}$ \\ aDepartment of Endocrine and Breast Surgery, The First Affiliated Hospital of Chongqing Medical University, \\ Chongqing, China; ${ }^{b}$ Chongqing Key Laboratory of Molecular Oncology and Epigenetics, The First Affiliated Hospital \\ of Chongqing Medical University, Chongqing, China; ' ${ }^{\circ}$ Diagnosis and Treatment Center of Breast Diseases, Shantou \\ Affiliated Hospital of Sun Yat-Sen University, Shantou, China
}

\section{Keywords}

Adjuvant chemotherapy · Adjuvant! Online · Breast cancer . Risk factors · SEER database

\begin{abstract}
Background: The purpose of this research was to investigate whether the modified version of Adjuvant! Online was able to omit chemotherapy (CT) for patients with hormone receptor (HR)-positive, human epidermal growth factor receptor 2 (HER2)-negative, and axillary node-negative breast cancer, who are defined as low clinical risk. Methods: From 2010 to 2014, HR-positive, HER2-negative, and node-negative breast cancer patients aged 50 years and older were retrieved from the Surveillance, Epidemiology, and End Results (SEER) 18 database. The propensity score matching method was applied between the no-CT and CT groups. Overall survival (OS) was evaluated using Kaplan-Meier analysis and compared across groups using a log-rank test. Results: A total of 48,857 patients were enrolled. After propensity score matching, the numbers of patients in the no-CT and CT groups were both 3,102 . The median follow-up period was 37 months. The 5 -year OS rates in the no-CT and CT groups were 92 and 91\%, respectively $(p=0.066)$. In the subgroup with a tumor score (tumor size added to tumor grade) of $2-3$, OS was signifi-
\end{abstract}

cantly higher in the no-CT group than in the CT group (93 vs. $90 \%, p<0.001)$. In the subgroup with a tumor score of 4 , OS was not different between these 2 groups (92 vs. 93\%, $p=$ 0.47). Conclusion: This retrospective study provides evidence that CT may not be beneficial to patients 50 years of age or older with HR-positive, HER2-negative, axillary nodenegative breast cancer and additionally defined as low clinical risk by a modified version of Adjuvant! Online.

(c) 2020 S. Karger AG, Basel

\section{Introduction}

Breast cancer is the most common malignant disease in women worldwide $[1,2]$. The prognosis of patients with breast cancer has been improved due to the advanced surgery and more effective adjuvant treatments $[3,4]$. In addition, advances in early screening strategies and equipment lead to an increasing detection rate of early-stage breast cancer $[5,6]$. Among them, patients with hormone receptor (HR)-positive and axillary node-negative tumors account for the largest proportion, which

Jiefeng Huang and Zhiyong Wu contributed equally to this work. 
Fig. 1. Patient selection program.

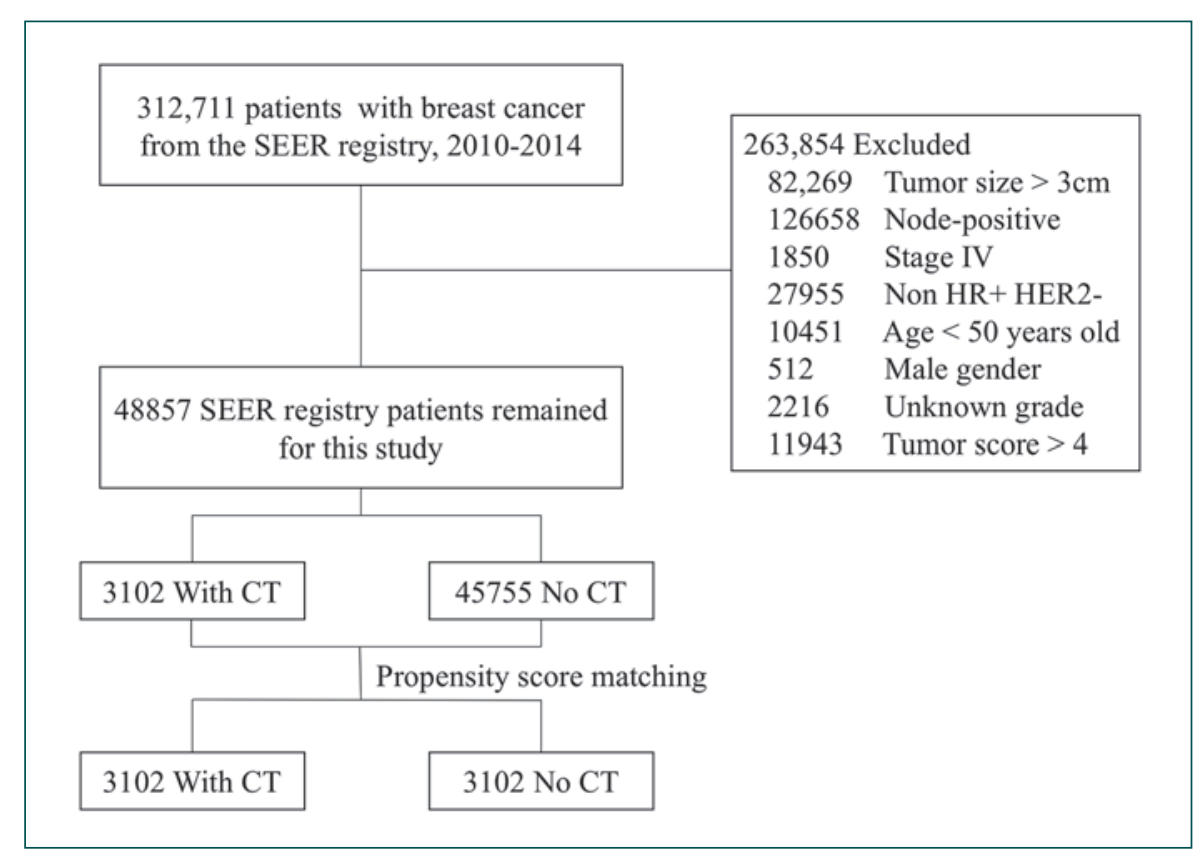

occurs in approximately half of invasive breast cancer in the United States [7]. Adjuvant chemotherapy (CT) is shown to reduce the risk of recurrence of early-stage breast cancer $[8,9]$. However, there is still much controversy regarding the effects of adjuvant $\mathrm{CT}$ in patients with HR-positive, human epidermal growth factor receptor 2 (HER2)-negative, and axillary node-negative tumors.

Accumulating evidence indicates that CT use has declined because of genetic testing $[10,11]$. The Trial Assigning Individualized Options for Treatment (TAILORx) concluded that women with HR-positive, HER2negative, axillarynode-negative, andlow-recurrence-score $(0-10)$ breast cancer had a very low risk of recurrence at 5 years with endocrine therapy alone [12]. Given this findings, at least $16 \%$ of the patients can avoid unnecessary adjuvant CT. Other evidence indicated that it is viable to omit CT by using clinicopathological features only. The 70-gene signature test (MammaPrint) showed that women who were at low clinical risk and high genomic risk received less benefit from the use of adjuvant CT [13]. In the Suppression of Ovarian Function Trial (SOFT), $47 \%$ of the patients did not receive CT according to low-risk clinicopathological features only. More than $96 \%$ of the patients were free from distant recurrence at 8 years in each treatment group [14], which means that it is feasible to omit CT in patients who are defined as low clinical risk in the absence of the 21-gene recurrence score. In China and many developing countries, the 21gene assay is unavailable due to the lack of standardization of testing, follow-up data, and appropriate laboratories. Thus, in clinical practice, whether the patients undergo adjuvant CT or not is usually determined by physicians through assessing the clinical characteristics or using medical tools.

There are lots of guidelines and methods to define the specific characteristics of low clinical risk, such as The National Comprehensive Cancer Network, AJCC Cancer Staging Manual, PREDICT-Plus, and Adjuvant! Online [15-17]. However, there is no uniform definition about low clinical risk in guidelines and tools. Thus, physicians may feel confused when selecting patients in whom adjuvant CT can be omitted in clinical practice. The modified version of Adjuvant! Online is easy to use and accessible for physicians. However, few studies have verified whether it can correctly predict the therapeutic regimen among breast cancer patients with low risk of recurrence.

\section{Patients and Methods}

\section{Study Population}

Patient data was retrieved from the SEER 18 Database using SEER*Stat, version 8.3.5 (October 2018 submission, Reference Identification: jiefengh). People were eligible if they were pathologically diagnosed with breast cancer from 2010 to 2014; were aged $\geq 50$ years at diagnosis; were axillary node negative, $H R$ positive, and HER 2 negative; had a tumor size no more than $3 \mathrm{~cm}$; and had a tumor score (tumor size added to tumor grade) no more than 4. Patients diagnosed before 2010 were excluded because of lack of HER2 status. Patients with incomplete information, including clinicopathological features, adjuvant CT, tumor grade, and follow-up months, were also excluded.

According to the Nottingham or Bloom-Richardson grade, we defined well-differentiated grade as grade I, moderately differentiated grade as grade II, and poorly differentiated, undifferentiated, 
Table 1. Clinical characteristics of all patients before and after PSM

\begin{tabular}{|c|c|c|c|c|c|c|}
\hline \multirow[t]{2}{*}{ Characteristics } & \multicolumn{3}{|l|}{ Before PSM } & \multicolumn{3}{|l|}{ After PSM } \\
\hline & $\begin{array}{l}\text { CT } \\
(n=3,102)\end{array}$ & $\begin{array}{l}\text { no-CT } \\
(n=45,755)\end{array}$ & $p$ value & $\begin{array}{l}\text { CT } \\
(n=3,102)\end{array}$ & $\begin{array}{l}\text { no-CT } \\
(n=3,102)\end{array}$ & $p$ value \\
\hline \multicolumn{7}{|l|}{ Insurance } \\
\hline Uninsured & $43(1.4)$ & $372(0.8)$ & 0.001 & $43(1.4)$ & $51(1.6)$ & 0.366 \\
\hline Insured & $3,008(97.0)$ & $44,455(97.2)$ & & $3,008(97.0)$ & 2,988 (96.3) & \\
\hline Unknown & $51(1.6)$ & $928(2.0)$ & & $51(1.6)$ & $63(2.0)$ & \\
\hline \multicolumn{7}{|l|}{ Race } \\
\hline White & $2,565(82.7)$ & $38,812(84.8)$ & $<0.001$ & $2,565(82.7)$ & $2,569(82.8)$ & 0.418 \\
\hline Black & $272(8.8)$ & 3,152 (6.9) & & $272(8.8)$ & $269(8.7)$ & \\
\hline Other & $254(8.2)$ & $3,533(7.7)$ & & $254(8.2)$ & $244(7.9)$ & \\
\hline Unknown & $11(0.4)$ & $258(0.6)$ & & $11(0.3)$ & $20(0.6)$ & \\
\hline \multicolumn{7}{|l|}{ Marital status } \\
\hline Married & $1,843(59.4)$ & $23,606(51.6)$ & $<0.001$ & $1,843(59.4)$ & $1,853(59.7)$ & 0.964 \\
\hline Unmarried & $1,075(34.7)$ & $19,221(42.0)$ & & $1,075(34.7)$ & $1,065(34.3)$ & \\
\hline Others & $184(5.9)$ & $2,928(6.4)$ & & $184(5.9)$ & $184(5.9)$ & \\
\hline \multicolumn{7}{|l|}{ Age } \\
\hline $50-59$ years & $1,474(47.5)$ & $10,211(22.3)$ & $<0.001$ & $1,474(47.5)$ & $1,468(47.3)$ & 0.977 \\
\hline $60-69$ years & $1,217(39.2)$ & $15,345(33.5)$ & & $1,217(39.2)$ & $1,211(39.0)$ & \\
\hline 70-79 years & 357 (11.5) & $12,493(27.3)$ & & 357 (11.5) & 367 (11.8) & \\
\hline$\geq 80$ & $54(1.7)$ & 7,706 (16.8) & & $54(1.7)$ & $56(1.8)$ & \\
\hline \multicolumn{7}{|l|}{ Histology } \\
\hline IDC & $2,662(85.8)$ & $37,992(83.0)$ & $<0.001$ & $2,662(85.8)$ & $2,654(85.6)$ & 0.828 \\
\hline ILC & 303 (9.8) & 4,400 (9.6) & & $303(9.8)$ & $316(10.2)$ & \\
\hline Other & $137(4.4)$ & $3,363(7.4)$ & & $137(4.4)$ & $132(4.2)$ & \\
\hline \multicolumn{7}{|l|}{ Surgery } \\
\hline Lumpectomy & $1,831(59.0)$ & $32,245(70.5)$ & $<0.001$ & $1,831(59.0)$ & $1,824(58.8)$ & 0.478 \\
\hline Mastectomy & $1,137(36.7)$ & $11,741(25.7)$ & & $1,137(36.7)$ & $1,124(36.2)$ & \\
\hline Other/unknown & $134(4.3)$ & $1,769(3.8)$ & & $134(4.3)$ & $154(5.0)$ & \\
\hline \multicolumn{7}{|l|}{ Tumor size } \\
\hline $1-10 \mathrm{~mm}$ & $1,211(39.0)$ & $23,503(51.4)$ & $<0.001$ & $1,211(39.0)$ & $1,206(38.9)$ & 0.590 \\
\hline $11-20 \mathrm{~mm}$ & $1,700(54.8)$ & $20,452(44.7)$ & & $1,700(54.8)$ & $1,723(55.5)$ & \\
\hline $21-30 \mathrm{~mm}$ & $191(6.2)$ & $1,800(3.9)$ & & $191(6.2)$ & $173(5.6)$ & \\
\hline \multicolumn{7}{|l|}{ Tumor grade } \\
\hline 1 & $886(28.6)$ & $21,774(47.6)$ & $<0.001$ & $886(28.6)$ & $850(27.4)$ & 0.431 \\
\hline 2 & $1,838(59.3)$ & $22,446(49.1)$ & & $1,838(59.2)$ & $1,888(60.9)$ & \\
\hline 3 & $378(12.1)$ & $1,535(3.3)$ & & $378(12.2)$ & 364 (11.7) & \\
\hline \multicolumn{7}{|l|}{ Tumor score ${ }^{\mathrm{a}}$} \\
\hline 2 & $293(9.5)$ & $11,856(25.9)$ & $<0.001$ & $293(9.4)$ & $278(9.0)$ & 0.728 \\
\hline 3 & $942(30.4)$ & $18,230(39.8)$ & & $942(30.4)$ & $963(31.0)$ & \\
\hline 4 & $1,867(60.1)$ & $15,669(34.3)$ & & $1,867(60.2)$ & $1,861(60.0)$ & \\
\hline \multicolumn{7}{|l|}{ Radiotherapy } \\
\hline No/unknown & $1,512(48.7)$ & $22,546(49.3)$ & 0.566 & $1,512(48.7)$ & $1,558(50.2)$ & 0.243 \\
\hline Yes & $1,590(51.3)$ & $23,209(50.7)$ & & $1,590(51.3)$ & $1,544(49.8)$ & \\
\hline
\end{tabular}

Values are $n$ (\%). PSM, propensity score matching; CT, chemotherapy; IDC, invasive ductal carcinoma; ILC, invasive lobular carcinoma. ${ }^{\text {a }}$ Tumor size added to tumor grade.

and anaplastic differentiation grades as grade III disease in the SEER 18 database. Our study used the modified version of Adjuvant! Online to define patients at low clinical risk, who must fulfill the following criteria: estrogen receptor-positive, HER2-negative, and axillary node-negative breast cancer, grade I and tumor size $\leq 3 \mathrm{~cm}$, or grade II and tumor size $\leq 2 \mathrm{~cm}$, or grade III and tumor size $\leq 1 \mathrm{~cm}$.

\section{Statistical Analyses}

Propensity score matching was used to adjust differences of the baseline characteristics between the CT and no-CT groups. In the CT and no-CT groups, a 1:1 propensity score matching method was applied in terms of age, race, insurance, marital status, tumor score (histologic grade added to tumor size), surgical operation method, and radiotherapy (yes or no). Pearson's $\chi^{2}$ test was used to compare 


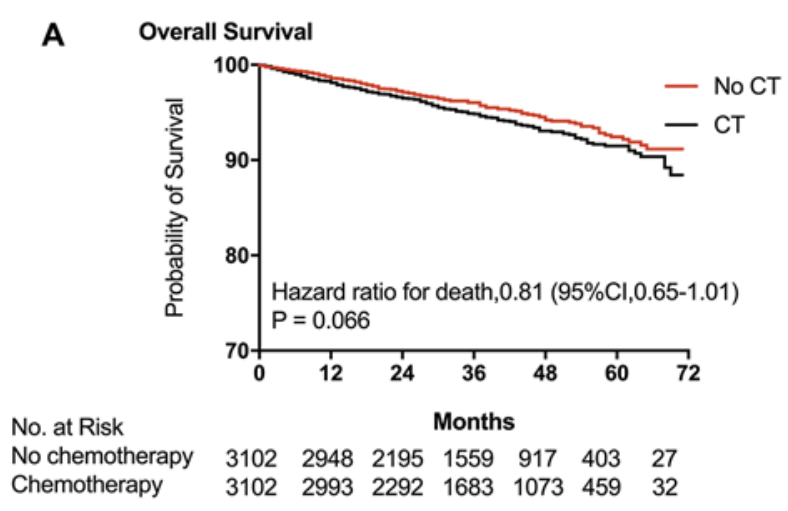

$\begin{array}{llllllll}\text { Chemotherapy } & 3102 & 2993 & 2292 & 1683 & 1073 & 459 & 32\end{array}$

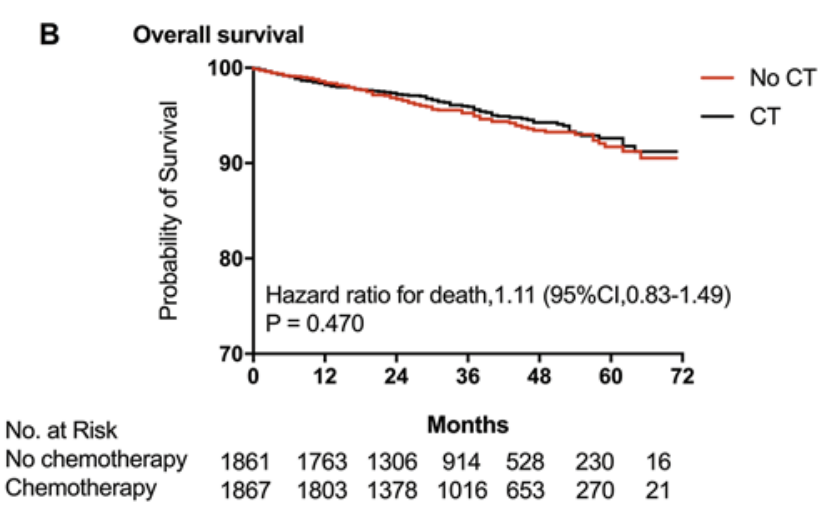

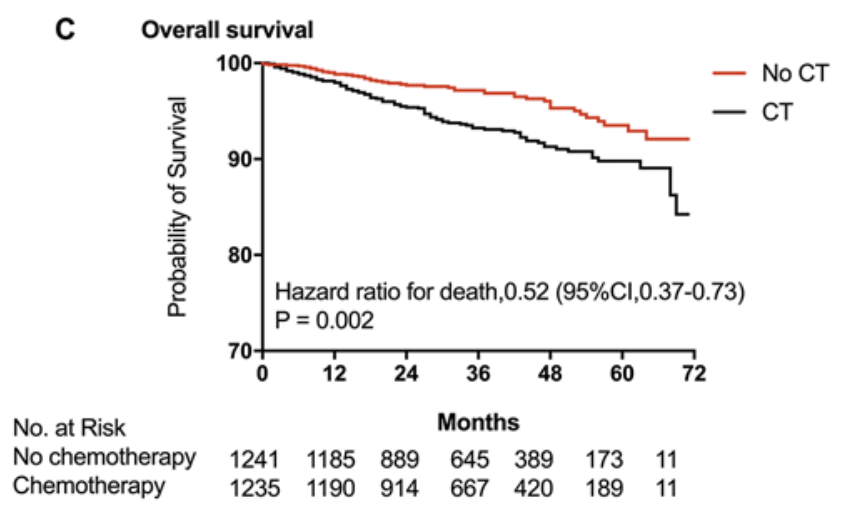

Fig. 2. Kaplan-Meier curves of the overall survival rate of patients with and without chemotherapy. A All patients. B Tumor score 4. C Tumor score 2-3.

the categorical variables between the two groups both before and after propensity score matching. The 5-year overall survival (OS) of the two groups was obtained using the Kaplan-Meier method and compared with the log-rank test. Multivariable Cox regression was performed to acquire adjusted hazard ratios with $95 \%$ confidence intervals. Statistical significance was set at $p<0.05$ (two-sided). Statistical analyses were performed using SPSS 25.0 software package and $\mathrm{R}$ version 3.3.0 software (http://www.r-project.org).

\section{Results}

\section{Patient Characteristics prior to Matching}

A total of 312,711 patients were retrieved between January 2010 and December 2014, of whom 48,857 were included in this study. The process of patient selection is given in Figure 1. The numbers of patients in the no-CT and CT groups were 45,755 (93.7\%) and 3,102 (6.3\%), respectively. The clinical characteristics of these patients are summarized in Table 1. After a median follow-up period of 37 months, there had been 105 events of breast cancerrelated death and 322 events of death due to all causes.
Patients in the CT group were generally younger than those in the no-CT group. The proportion of patients aged 70 years or older was larger in the no-CT group compared to the CT group ( 27.3 vs. $11.5 \%$; $p<0.001$ ). Furthermore, patients in the CT group had a more advanced tumor stage. We stratified patients according to tumor size and tumor grade. As for tumor size, the proportions of patients in the groups with tumors of 11-20 and 21-30 $\mathrm{mm}$ were significantly higher in the CT group than in the no-CT group (54.8 vs. $44.7 \%$; 6.2 vs. $3.9 \%$; $p<0.001$ ). As for tumor grade, the proportions of patients with tumors of grade 2 and 3 were 59.3 and $12.2 \%$, respectively, in the CT group as compared with 49.1 and $3.4 \%$ the in no-CT group $(p<0.001)$. As expected, there was a similar trend for tumor score (tumor size added to tumor grade): the proportion of patients assessed as score 4 was larger in the CT group than in the no-CT group (60.2 vs. $34.3 \%$; $p<$ $0.001)$. For treatment procedures, the no-CT group had a higher rate of breast-conserving surgery than the CT group (70.5 vs. $59.0 \%$ ). But there was no significant difference in radiotherapy between these two groups. 
Table 2. Univariable and multivariable analysis of OS rates stratified by demographic data

\begin{tabular}{|c|c|c|c|c|c|c|}
\hline \multirow[t]{2}{*}{ Characteristics } & \multicolumn{3}{|l|}{ Univariate } & \multicolumn{3}{|c|}{ Multivariate } \\
\hline & 5-year OS & $95 \%$ CI & $p$ value & aHR & $95 \%$ CI & $p$ value \\
\hline \multicolumn{7}{|l|}{ Insurance } \\
\hline Uninsured & 92 & $91.92-92.08$ & 0.374 & & & \\
\hline Insured & 92 & $91.98-92.02$ & & & & \\
\hline Unknown & 89 & $88.92-89.08$ & & & & \\
\hline \multicolumn{7}{|l|}{ Marital status } \\
\hline Married & 94 & $93.98-94.02$ & $<0.001$ & Reference & & \\
\hline Unmarried & 89 & $88.98-89.02$ & & 0.97 & $0.60-1.57$ & 0.90 \\
\hline Others & 91 & $90.96-91.04$ & & 1.55 & $0.96-2.50$ & 0.072 \\
\hline \multicolumn{7}{|l|}{ Age } \\
\hline $50-59$ years & 95 & $94.98-95.02$ & $<0.001$ & Reference & & \\
\hline $60-69$ years & 93 & $92.98-93.02$ & & 1.55 & $1.17-2.04$ & 0.002 \\
\hline $70-79$ years & 83 & $82.96-83.04$ & & 3.06 & $2.26-4.16$ & $<0.001$ \\
\hline$\geq 80$ & 55 & $54.86-55.14$ & & 5.89 & $3.88-8.95$ & $<0.001$ \\
\hline \multicolumn{7}{|l|}{ Race } \\
\hline White & 92 & $91.98-92.02$ & 0.580 & & & \\
\hline Black & 92 & $91.96-92.04$ & & & & \\
\hline Other & 92 & $91.96-92.04$ & & & & \\
\hline Unknown & 100 & & & & & \\
\hline \multicolumn{7}{|l|}{ Histology } \\
\hline IDC & 92 & $91.98-92.02$ & 0.853 & & & \\
\hline ILC & 92 & $91.96-92.04$ & & & & \\
\hline Other & 92 & $91.96-92.04$ & & & & \\
\hline \multicolumn{7}{|l|}{ Surgery } \\
\hline Lumpectomy & 95 & $95.00-95.00$ & $<0.001$ & Reference & & \\
\hline Mastectomy & 91 & $90.98-91.02$ & & 0.89 & $0.64-1.22$ & 0.46 \\
\hline Others & 55 & $54.92-55.08$ & & 6.23 & $4.41-8.80$ & $<0.001$ \\
\hline \multicolumn{7}{|l|}{ Tumor size } \\
\hline $1-10 \mathrm{~mm}$ & 92 & $91.98-92.02$ & 0.132 & & & \\
\hline $11-20 \mathrm{~mm}$ & 93 & $92.98-93.02$ & & & & \\
\hline $21-30 \mathrm{~mm}$ & 89 & $88.96-89.04$ & & & & \\
\hline \multicolumn{7}{|l|}{ Tumor grade } \\
\hline 1 & 92 & $91.98-92.02$ & 0.570 & & & \\
\hline 2 & 92 & $91.98-92.02$ & & & & \\
\hline 3 & 93 & $92.98-93.02$ & & & & \\
\hline \multicolumn{7}{|l|}{ Tumor score ${ }^{a}$} \\
\hline 2 & 92 & $91.96-92.04$ & 0.678 & & & \\
\hline 3 & 92 & $91.98-92.02$ & & & & \\
\hline 4 & 92 & $91.98-92.02$ & & & & \\
\hline \multicolumn{7}{|l|}{ Radiotherapy } \\
\hline No/unknown & 87 & $86.98-87.02$ & $<0.001$ & Reference & & \\
\hline Yes & 97 & $97.00-97.00$ & & 0.36 & $0.25-0.51$ & $<0.001$ \\
\hline
\end{tabular}

Values are \%. OS, overall survival; CI, confidence interval; aHR, adjusted hazard ratio; IDC, invasive ductal carcinoma; ILC, invasive lobular carcinoma. ${ }^{a}$ Tumor size added to tumor grade.

\section{Patient Matching}

After 1:1 propensity score matching, 3,102 patients in each group were enrolled. In the matched groups, there was no significant difference in any of the variables, including average age $(p=0.97)$, race $(p=0.45)$, marital status $(p=0.91)$, histology $(p=0.91)$, surgery $(p=0.48)$, tumor size $(p=0.59)$, tumor grade $(p=0.43)$, and tumor score $(p=0.73)$.

Univariate analysis of OS was performed after propensity score matching. Insurance, race, histology, tumor 
size, tumor grade, and tumor score were insignificant indicators of the survival prognosis, while married status, younger age, breast conserving-surgery, and radiotherapy indicated a significantly better prognosis.

In the multivariate COX analysis, marital status, age, surgery, and radiotherapy were included. As a result, younger age (hazard ratios for 60-69, 70-79, and $\geq 80$ years compared with $50-59$ years were $1.55,3.06$, and 5.89 , respectively; $p$ values were $0.002,<0.001$, and $<0.001$, respectively) and received radiotherapy (hazard ratio 0.36 ; $p<0.001$ ) were the independent favorable prognostic factors for OS. The complete results are listed in Table 2.

\section{Overall Survival}

The 5-year OS was compared between the no-CT and CT groups and then in each risk subgroup stratified by tumor score. The 5-year OS rates in the no-CT and CT groups were 92 and $91 \%$, respectively (hazard ratio 0.81 ; $p=0.066$; Fig. 2A).

In the risk subgroup with a tumor score of 4 , OS rates were not different between these two groups ( 92 vs. $93 \%$, hazard ratio $1.11 ; p=0.47$; Fig. $2 \mathrm{~B}$ ). In the risk subgroup with a tumor score of $2-3$, OS was significantly higher in the no-CT group than in the CT group ( 93 vs. $90 \%$, hazard ratio $0.52 ; p<0.001$; Fig. $2 \mathrm{C}$ ).

\section{Discussion}

In this retrospective study, we found that CT may not be favorable for those patients with HR-positive, HER2-negative, axillary node-negative breast cancer, who were additionally defined as low clinical risk by a modified version of Adjuvant! Online, especially in the risk subgroup with a tumor score of 2-3, in which CT might reduce the survival rate because of a toxic effect. This finding confirms that the modified version of Adjuvant! Online is reliable and could be used to determine whether the therapeutic regimen is sufficient for a certain type of breast cancer patients.

In the MINDACT (Microarray In Node-negative and 1-3 node positive Disease may Avoid ChemoTherapy) trial [13], patients at low clinical risk (defined by the modified version of Adjuvant! Online) and high genomic risk received no benefit from the use of adjuvant CT. Among the 592 patients, 581 (98.1\%) had tumors measuring $<2$ cm; 577 (97.5\%) were node negative; 535 (90.4\%) were estrogen receptor positive; $518(87.5 \%)$ were HER2 negative; and $506(85.5 \%)$ had tumor grade 1 or 2.

In the TAILORx trail, $16 \%$ of the women had a low recurrence score (0-10), and $69 \%$ had a midrange recurrence score (11-25). The results showed that patients with a low recurrence score, treated with endocrine therapy alone, had a very low rate of recurrence within 5 years, and the patients with a midrange recurrence score, diagnosed with
HR-positive, HER2-negative, axillary node-negative breast cancer, received similar benefits from endocrine therapy and chemoendocrine therapy $[11,12]$. In the midrange recurrence score group, among women who received endocrine therapy and chemoendocrine therapy, 74 and $73 \%$, respectively, were at low clinical risk assessed with the same clinical risk definition as used in the MINDACT trail [11]. Thus, with the basis of the results of the MINDACT trail and the TAILORx trail, we found it logical to use the modified version of Adjuvant! Online to determine the therapeutic regimen for patients with HR-positive, HER2negative, axillary node-negative breast cancer. According to the latest results of the TAILORx trail [11], the CT benefit for invasive disease-free survival is associated with both recurrence score and age. There are some benefits for CT received by women 50 years of age or younger and with a recurrence score of 16-25. Thus, women younger than 50 years were excluded from this study.

There are several advantages in using the modified version of Adjuvant! Online. First, it is easy to operate for physicians because it is not prerequisite to sign into sites. Second, the website of Adjuvant! Online (www.adjuvantonline.com) is updated regularly, since it did not consider the HER2 status before. Thus, the website needs a long period of time to update the data and, more importantly, to revise their results including 10 -year risk and effectiveness of adjuvant therapy. Fortunately, the information from this website shows that this tool will be coming soon. For the recent period, it is time-saving for physicians and patients to use the modified version of Adjuvant! Online and it is easily accessible. However, there are few studies that have verified whether the modified version of Adjuvant! Online can correctly predict the therapeutic regimen for patients with low-risk tumors.

This study has several limitations. First, the SEER database started in 1973, while there was no HER2 status until 2010. In order to capture more cases and ensure a median follow-up time $\geq 3$ years, we recruited the patients from 2010 to 2014. The clinical judgment considerations, such as genetic testing results, are underreported in the SEER database; therefore, there might be a selection bias for the patients enrolled. However, Kurian et al. [18] reported that half of the patients with HR-positive, HER2-negative, and axillary node-negative breast cancer did not receive 21gene recurrence score testing in the SEER registries. Parsons et al. [10] reported that more than $40 \%$ of early-stage patients did not receive 21-gene recurrence score testing in the National Cancer Data Base. Second, we could not retrieve the information on local recurrence and distant metastasis from the SEER registries so that these outcomes could not be evaluated. Third, the SEER database does not freely provide information on hormone therapy and CT regimens for researchers abroad, so the specific effect of systemic therapy also could not be evaluated. 
In conclusion, CT may not be beneficial to those patients with HR-positive, HER2-negative, axillary nodenegative breast cancer and additionally defined as low clinical risk by the modified version of Adjuvant! Online, which is a predictive tool for personalized therapeutic decision-making for patients with low-risk breast cancer.

\section{Acknowledgements}

We thank the SEER Research Database Team for providing the breast cancer data.

\section{Statement of Ethics}

A signed research data agreement form was provided to the SEER program before our study, and we were granted approval to access and analyze the SEER database, which is a public database that does not require ethical approval.

\section{Disclosure Statement}

The authors declare that they have no competing interests.

\section{References}

1 Jemal A, Center MM, DeSantis C, Ward EM. Global patterns of cancer incidence and mortality rates and trends. Cancer Epidemiol Biomarkers Prev. 2010 Aug;19(8):1893-907.

2 Bray F, Ferlay J, Soerjomataram I, Siegel RL, Torre LA, Jemal A. Global cancer statistics 2018: GLOBOCAN estimates of incidence and mortality worldwide for 36 cancers in 185 countries. CA Cancer J Clin. 2018 Nov;68(6): 394-424.

3 Cossetti RJ, Tyldesley SK, Speers CH, Zheng Y, Gelmon KA. Comparison of breast cancer recurrence and outcome patterns between patients treated from 1986 to 1992 and from 2004 to 2008. J Clin Oncol. 2015 Jan;33(1):65-73.

4 Hendrick RE, Baker JA, Helvie MA. Breast cancer deaths averted over 3 decades. Cancer. 2019 May;125(9):1482-8.

5 US Preventive Services Task Force. Screening for breast cancer: U.S. Preventive Services Task Force recommendation statement. Ann Intern Med. 2009 Nov; 151(10):716-26, $\mathrm{W}-236$.

6 Moss SM, Wale C, Smith R, Evans A, Cuckle H, Duffy SW. Effect of mammographic screening from age 40 years on breast cancer mortality in the UK Age trial at 17 years' follow-up: a randomised controlled trial. Lancet Oncol. 2015 Sep;16(9):1123-32.

7 Howlader N, Altekruse SF, Li CI, Chen VW, Clarke CA, Ries LA, et al. US incidence of breast cancer subtypes defined by joint hormone receptor and HER2 status. J Natl Cancer Inst. 2014 Apr;106(5):106.
8 Early Breast Cancer Trialists' Collaborative Group (EBCTCG). Effects of chemotherapy and hormonal therapy for early breast cancer on recurrence and 15-year survival: an overview of the randomised trials. Lancet. 2005 May;365(9472):1687-717.

9 Mansour EG, Gray R, Shatila AH, Tormey DC, Cooper MR, Osborne CK, et al. Survival advantage of adjuvant chemotherapy in highrisk node-negative breast cancer: ten-year analysis-an intergroup study. J Clin Oncol. 1998 Nov; 16(11):3486-92.

10 Parsons BM, Landercasper J, Smith AL, Go RS, Borgert AJ, Dietrich LL. 21-Gene recurrence score decreases receipt of chemotherapy in ER+ early-stage breast cancer: an analysis of the NCDB 2010-2013. Breast Cancer Res Treat. 2016 Sep;159(2):315-26.

11 Sparano JA, Gray RJ, Makower DF, Pritchard KI, Albain KS, Hayes DF, et al. Adjuvant Chemotherapy Guided by a 21-Gene Expression Assay in Breast Cancer. N Engl J Med. 2018 Jul;379(2):111-21.

12 Sparano JA, Gray RJ, Makower DF, Pritchard KI, Albain KS, Hayes DF, et al. Prospective Validation of a 21-Gene Expression Assay in Breast Cancer. N Engl J Med. 2015 Nov; 373(21):2005-14.

13 Cardoso F, van't Veer LJ, Bogaerts J, Slaets L, Viale G, Delaloge S, et al.; MINDACT Investigators. 70-Gene Signature as an Aid to Treatment Decisions in Early-Stage Breast Cancer. N Engl J Med. 2016 Aug;375(8):71729.
14 Francis PA, Pagani O, Fleming GF, Walley BA, Colleoni M, Láng I, et al.; SOFT and TEXT Investigators and the International Breast Cancer Study Group. Tailoring Adjuvant Endocrine Therapy for Premenopausal Breast Cancer. N Engl J Med. 2018 Jul;379(2): 122-37.

15 Giuliano AE, Connolly JL, Edge SB, Mittendorf EA, Rugo HS, Solin LJ, et al. Breast Cancer-Major changes in the American Joint Committee on Cancer eighth edition cancer staging manual. CA Cancer J Clin. 2017 Jul; 67(4):290-303.

16 de Glas NA, van de Water W, Engelhardt EG, Bastiaannet E, de Craen AJ, Kroep JR, et al. Validity of Adjuvant! Online program in older patients with breast cancer: a populationbased study. Lancet Oncol. 2014 Jun;15(7): 722-9.

17 Oakman C, Santarpia L, Di Leo A. Breast cancer assessment tools and optimizing adjuvant therapy. Nat Rev Clin Oncol. 2010 Dec;7(12): 725-32.

18 Kurian AW, Bondarenko I, Jagsi R, Friese CR, McLeod MC, Hawley ST, et al. Recent Trends in Chemotherapy Use and Oncologists' Treatment Recommendations for Early-Stage Breast Cancer. J Natl Cancer Inst. 2018 May; 110(5):493-500. 